\title{
Official statistical leadership at the crossroads again: An information age perspective
}

\author{
Ramachandran Ramasamy \\ Policy, Capability and Research, The National ICT Association of Malaysia (PIKOM), E1, Empire Damansara, \\ No.2, Jalan PJU 8/8A, Damansara Perdana, 47820 Petaling Jaya, Selangor, Malaysia \\ Tel.: +6 034065 0078; Fax: +6 034065 0079; E-mail: ramachan@pikom.org.my
}

\begin{abstract}
This paper expounds the need for collating knowledge based economy (KBE) indicators in a holistic manner under the official statistical system. The paper argues, the official statistical user needs and demands have changed drastically in recent years. Rapid information communications technological (ICT) upheavals have made profound impacts on all spheres of life, as such the way one work, learn, interact, transact and communicate have embraced changes unprecedented in human history. The changes challenge not only public policy formulation activities but also raise questions on validity of certain statistical concepts and definitions as well as data aptness. The current official statistical system is based on agriculture and industrial settings and lack adequacy and comprehensiveness in depicting the information age developments. Beginning with the advent of online connectivity and real time interactive Internet features in early nineties, the KBE is incrementally shaped by broadband communication; borderless networking irrespective of geography and time; intensification of digitization processes and contents; miniaturization of computing devices enhancing business mobility and agility; new transactional and analytical models like outsourcing, cloud computing, cognizance computing, big data analytics and pay as you use e-services increasingly typify contemporary businesses. As such, changes in policy institutions, organizational structures, governance processes, people's lifestyles and millennial workforce new demands and behaviours have emerged, thus exerting unduly pressures not only on public policy strategies but also on national statistical system. Reckoning the imperatives, the paper is making a clarion call to scrutinize, review and realign the current official statistical system, including incepting totally new statistical surveys on gauging KBE. In support of the claim, the paper highlights the Malaysian KBE statistical experiences, wherever deemed relevant.
\end{abstract}

Keywords: Knowledge based economy, official statistical system, information communications technology (ICT), KBE statistical experience

\section{Introduction}

This paper looks into the activities and challenges associated with statistical compilation in the information age, in particular indicators on information and communications technology (ICT) and the knowledgebased economy (KBE). User demand for statistics has begun to shift towards $\mathrm{KBE}$ since the commercial emergence of Internet technology in the early nineties, which is taken as the beginning of the information age [14,34,36]. The information age is characterized by online connectivity, real time interactive features and digitization processes as well as the convergence of ICT technology, institutions, people and processes [7,17]. Consequently, the information age has produced numerous levels of digitized products and services as well as new business models and human behaviour that have set a precedent in human history [22,23]. As cited by Drucker, the steam engine, triggered the industrial revolution just as the computer triggered the information revolution [12]. Drucker has also pointed out that in the early nineteenth century, the steam engine was only invented as a product and that it was the railroad that truly revolutionized the economy and rapidly changed the mental geography in helping humanity to master distance. Drucker has also noted that the computer has helped mankind to do things faster and cheaper, and more efficiently and effectively. But the computer had not helped mankind to do new and transformative things until e-commerce emerged 
as a key factor in the information revolution; in the same way that the railroad was to the industrial revolution. In this evolutionary process, data, information and knowledge as well as the related networks and nexus have become key components in business and development equations, over and above the traditional factors of production namely land, labour, capital and manufacturing technology $[1,14,24,25]$. The borderless phenomena has not only brought new opportunities, but also came with new threats, in particular cyber threats in various forms and shades, thus posing challenges to traditional societal values, cultures and lifestyle as well as a nation's sovereignty $[5,12,22,36]$.

\section{Knowledge-based economy (KBE) as new age public policy imperative}

The industrial era saw the emergence of factories; mechanization of mass production; demand for skilled and semi-skilled professionals as well as lowcost labour; output and inputs systems; a new breed of consumers for manufactured products and services as opposed to agricultural-based subsistence consumption; and the creation of a working class and nuclear family since industry took the worker out of the home $[5,12,25]$. Similarly, the information era has been continuously shaping society, economy and governance as well as individual lifestyle and behaviour in its own unique way. As such, the way one works, communicates, interacts, performs business transactions, delivers goods and services, networks and learn have been undergoing tremendous changes technologically, structurally and institutionally. Some upheavals are disruptive and revolutionary, and are unprecedented in human history $[8,9]$, to name a few as follows.

\subsection{Disruptions in ICT product development}

In the product market, mobile phones have pushed the landlines to the back; digital word processing has consigned typewriters to obsolescence; the Sony Walkman once dominating the music market has been irrevocably replaced by Apple's iPod; and the Netflix online video service has usurped other forms of broadcasting. The profound impact is not only being experienced in product markets, but also in the provision of services [35]. Specifically, the intensification of the digitization processes taking place irrespective of time, geography, cultures and traditions [27] has given rise to new businesses and behavioural mod- els. Traditional postal services have become less appealing with the introduction of e-mail and short message services (SMS), especially among the youths. Internet driven mobile commerce makes online shopping a lot easier and convenient, as opposed to physical travelling which is presumably costly and timeconsuming. E-commerce and mobile commerce, supported by subscription-based services entailing pay-asyou-use or advertisement-based models along with Internet banking facilities have increasingly become typical features in contemporary business transactions.

\subsection{Disruptions in ICT services provision}

Cloud computing, which has driven down ICT infrastructure costs and the dependency on computing experts and proprietary software, has facilitated technology adoption by small and medium-sized enterprises (SME) et cetera $[3,6,20]$. Indeed, the provision of infrastructure, platform, database, information and software as a service, has enabled a cost effective and efficient implementation of cloud computing. The deployment of wearable technology, like consumer wearables to monitor employee movements, time monitoring, navigation, tracking and emergency alerts for security and health diagnostics tools, has become commonplace in the workplace. Big data analytics providing seamless and real time business intelligence, culled from the integration of backend operations systems such as Enterprise Resource Planning (ERP), Customer Relationship Manager (CRM) and Supply Chain Management (SCM) with internal employee administrative records and external records outside the organization like Linked-In, are creating new work processes and human resource nuances.

\subsection{Emergence of new institutions}

In a bid to harness the new age phenomena, a number of ministerial and organizational portfolios have reinvented their functions, rules, roles, regulations, process, procedures and mechanisms, hierarchies and divisions of responsibility. Specifically in Malaysia, the information age has witnessed the emergence of several new policy and development institutions especially in the mid-nineties. The first and foremost institution established was the NITC in 1994 under the chairmanship of the Honorable Prime Minister of Malaysia [16]. Since then, the NITC has been the primary advisor and consultant to the government on all matters pertaining to ICT. As such, in 1996, 
the NITC launched the National Information Technology Agenda (NITA), which provided a comprehensive framework for spearheading the KBE and KBS. In essence, the framework entailed a three-pronged approach: development of people, info-structure (hard and soft infrastructure) and skills such as education, creative and innovation skills; research and development capabilities, computing, telecommunication, broadcasting, transmission and network products and services; and cyber laws, cyber security, multimedia content applications etc.

Recognizing the convergence of telecommunications, broadcasting and computing, the government has also created a number of new institutions since 1998. A dedicated ministry has been established to oversee the provision of telecommunications infrastructure, computer and content development activities. Currently, these functions are under the purview of the Ministry of Communications and Multimedia Malaysia (MCMM). Nonetheless, ICT policy functions still reside with the Ministry of Science, Technology and Innovation (MOSTI). Prior to this ministerial coordination, the ICT functions were fragmented and placed under various ministries. The Multimedia Development Corporation, now branded as $\mathrm{MDeC}$, was set up in 1998 as a new government-linked corporation to oversee the formulation and implementation of the MSC Malaysia programme (formerly known as Multimedia Development Corporation Programme). Similarly, the Malaysian Communications and Multimedia Commission (MCMC) was set up as a new entity in 1998, to be in charge of regulatory and licensing activities pertaining to the provision of telecommunication, broadcasting and content services.

\subsection{Changes in mainstream agencies}

A number of traditional institutions have also reviewed and realigned their roles and functions to include ICT segments. For instance, the provision of telecommunications infrastructure was once tasked under a department before the liberalization of telecommunications policy in 1994. In particular, the Malaysian Technology Development Corporation (MTDC), among many others, assumed the role of commercialization of ICT research and development; SIRIM (formerly known as Standards and Industrial Research Institute of Malaysia) expanded its scope to safeguard the standards and quality of local ICT products and services; the Malaysia External Trade Development Corporation (MATRADE) extended its role to ICT export promotion activities; SME Corp provided the requisite financial support for SMEs to expand their businesses; and MIMOS undertook ICT research besides its traditional research role for the micro-electronics sector. The Malaysian Productivity Corporation (MPC) has also in recent years begun to explore productivity elements pertaining to communications, besides monitoring, measuring and evaluating ICT manufacturing aspects. After the introduction of banking online services, Bank Negara Malaysia (BNM) has been regularly publishing statistics on Internet and mobile banking since 2005, besides credit card services information and ICT trade-in- services. The institutional evolution over the years has indicated that users of ICT statistics have also expanded within the Government domain. Needless to say, the private sector would have joined the ranks of the users of ICT data pertaining to trade, investment and employment; indicating the growing demand for ICT and associated data.

\section{Major shift in public policy thrust}

In response to the new age imperatives, the Government of Malaysia pronounced a Knowledge-Based Economy (KBE) [16] as the main tenet of the Third Outline Perspective Plan (2001-2010), popularly abbreviated as OPP3 with emphasis on ICT as the major development thrust [2,36]. The earlier long-term development plans were OPP1 (1971-1990) and OPP2 (1991-2000), which focused on agricultural and industry development respectively. Hence, this was considered a major policy shift in ushering the nation from an agro-based economy, then industrial economy to one based on knowledge and innovation in which contemporary ICT assumed an explicit role as driver and enabler of society and economy. Driven by such a policy vision and direction, the Government has initiated a number of ICT programmes to address challenges such as the liberalization of the telecommunication sector, harnessing convergence of technology, provision of broadband, bridging digital divide, producing graduates in adequate number in the field of ICT, engineering and knowledge economy, privatization of the education sector, promoting new age business models like outsourcing and e-commerce as new sources of growth sectors, establishing research and development funding directed towards innovation, and patenting and commercialization activities [16]. It has been a while since the KBE initiatives have been put in place; how- 
ever, the challenge still remains as to what extent to which official statistical systems in the country have risen to the occasion in gauging the impact and effects of the new age phenomena on society, economy and governance as well as lifestyle and behaviour of individuals. Recognizing the policy imperatives, this paper is poised to expound the leadership in official statistics within the context of understanding the notion of KBE and its measurability aspects; gaps in gauging the KBE dimensions in the current official statistical system and the emerging statistical measurement nuances as well as way forward strategies.

\section{Official statistical leadership at the crossroads again}

It is clear that the role of the official statistical system and more so, its leadership in determining the new direction is at the crossroads again. Starting with its first complete census inception in 1911 [38], followed by the first statistical compilation of national accounts in 1962/63 using a value-added expenditure approach, the Malaysian statistical systems have come of age [26]. In the sixties, the official statistical system successfully met the policy needs of a laissez-faire economy based on rural economic development followed by the planning needs of an agro-based economy in the seventies and heavy industrialization strategies in eighties and thereafter.

Despite major shifts in economic policies and development thrusts, the main motivation and aspiration to produce official statistics have essentially remained the same until today [15]. Increasing revenue from rising productivity and competitiveness, support for public policy formulation and development programme implementation and better delivery of public services of high quality have been the top priority in the provision and usage of official statistics. As societies become more complex, the pressure to widen the range of official statistics has also increased, in particular, statistics that support the democratic accountability of Governments to their peoples. In this endeavour when environmental degradation and climate change challenges have become a major concern among policy makers and development practitioners worldwide, compiling environment statistics have become the norm and typically features in the official statistics system in Malaysia, as well globally in other countries.

Like in the past, the official statistical system is once again at the crossroads for a review and realignment when the current official statistical systems founded on agro-industrial settings could not meet the policy demands of the information age [32]. Recognizing the new age policy imperatives and fast-emerging development practices, the Government of Malaysia has incorporated a top-down measure in the Eighth Malaysia Plan (2000-2005), calling for a new set of indicators aimed at measuring contemporary ICT and KBE developments; the policy excerpt is shown below:

"Promoting R\&D on Soft Factors (Chapter 13, Eighth Malaysia Plan (2000-2005)

13.66 The contemporary information and communication products and services such as radio, television, cellular phones, e-mail, Internet, computers and video conferencing are changing the way individuals, organizations and societies are communicating, interacting, doing business transactions and learning. Recognizing the ubiquity and the nature of emerging Information Age issues and challenges, the Government, in collaboration with the public policy and higher learning institutions, will undertake research on the soft elements of ICT development. These include monitoring and evaluating ICT impact on public, private and household sectors; Internet subscription and usage profile; emerging work culture characterized by the rise of knowledge workers and teleworking modes; measuring knowledge developments and the formation of information and knowledge-based societies through Knowledge Imperative Index (KIX) and Knowledge Economy Model (KEM) initiatives; and realigning trade, industry, product and occupational classifications to define the information sector".

\section{Measurability aspect of the KBE}

Features and characteristics of the KBE are not only technology-centric items but also entails diffusion, usage pattern and behavioural aspects impacting profoundly on all levels of society, economy and governance that were previously not measured under the agro-industrial statistical measurement system [32,34]. New policy and business demands pertaining to the $\mathrm{KBE}$ can be surmised as the provision of broadband infrastructure; diffusion of ICT products and services among individuals, household, establishments, government and learning sectors; online connectivity and real time interactivity elements in communications, networking and business transactions; 
lifestyle infused with digitized products and services as well as delivery processes; the informatization phenomena and knowledge processing giving rise to policy and business intelligence analytics; new business models promulgating outsourcing, cloud computing, e-commerce, mobile commerce, online/Internet banking, pay-as-you-use and big data analytics; the rise of knowledge workers; demands of millennials like buy-your-own-device (BYOD) and teleworking practices posing challenges to the traditional human resources and inventory practices; miniaturization of devices taking the shape of wearable technology and embedded Internet of things (IOT); green computing addressing environmental challenges; ICT-led innovation, R\&D, commercialization and patenting; provision of e-government services, e-democracy and online citizen participation in governance and decisionmaking processes; and lately, cognizance computing and everyone-to-everyone economy (E2E) model used in addressing customer aspirations and quality improvements [3,6,20,35].

These activities create, share and distribute data and information in a prolific manner unprecedented in human history [32,34]. When data and information are internalized and converted into knowledge, it creates new economic, social and public values [31,34] that are surrogates for the KBE. Converting data and information into knowledge is not a new activity; on the contrary, it has been in existence since the beginning of human civilization. As outlined above, the technology tools, assemblages and processes as well as the speed and pace used in knowledge activities have changed over time and in its contemporary form, ICT plays an explicit role.

However, like many other items, knowledge is an abstract item. It cannot be measured using any gadget like a thermometer or formula for measuring gravity or statistical criterion "worked at least one hour in gainful employment during reference work" for measuring work in relation to labour force participation, unemployment rate and under employment rates. However, monitoring, measuring and evaluating features, characteristics, attributes and assemblages of contemporary ICT as well as its usage patterns, impacts and effects on all spheres of life can be construed to provide a surrogate measure for KBE activities. Like any other statistical measures creation, deployment and usage of knowledge driven by ICT can be measured and monitored over time and even by geography.

\section{KBE measurement challenges}

Despite top-down advocacy and intervention, implementation to realize a full-fledged knowledge economy has fallen short of the envisaged policy aspirations. The shortfall in realizing a full-fledged ICT and KBE indicators could be attributed to various reasons, as follows.

\subsection{Weak institutional support}

Among others, mainstream policy formulators and planners as well as the statistical community have failed to fully comprehend the potential capability of contemporary ICT beyond technology, that is, as a driver, enabler and transformer of economy, society and governance processes as well as lifestyle and behaviour of individuals [16,33]. Consequently, the statistical aspiration has failed to garner continuity in political support and policy will at the strategic level. The statistical aspiration has been further hampered at the implementation level as administrative commitments have also fallen short in ensuring adequate resources allocation and appropriation. To date, the compilation of new-age statistics has not gained any explicit programme status in the national development agenda. As such, no explicit allocation has been allotted in the annual budget system for compiling KBE indicators except for limited ICT statistical compilation. The current compilation and publication of ICT statistics are primarily undertaken by MCMC and the Department of Statistics Malaysia (DoSM). Being a regulatory body, MCMC has been compiling a number of ICT indicators but this is confined to the coverage of telecommunications and content regulatory activities. DoSM also compiles a number of ICT indicators as an integral activity of the department's long-established statistical surveys like ICT penetration at household level during the annual national household surveys. Similarly, ICT manufacturing in terms of input, output, and value-added services are compiled vide annual and monthly manufacturing surveys. But, their current ICT compilations are very much technology-centric, and lacks the knowledge economy or knowledge society perspectives, in particular the impact and outcomes of ICT on society and economy. Nonetheless, the implementation of new age technology indicators warrants inter-disciplinary subject matter expertise.

\subsection{Inadequate capacity building endeavour}

Just as a coin has two sides, the problem of scanty and limited data in the ICT sector in Malaysia can be 
viewed from both the policy formulator and data producer angles. First and foremost, the policy formulators and development planners should have been cognizant from the outset of planning of the dire need to adapt new-age data collation mechanisms and processes. It may be a difficult task for a developing or a newly-industrialized country like Malaysia to embark upon new statistical initiatives, which require a great deal of effort and expert knowledge in coping with the nuances of emerging subject matters like contemporary ICT. However, the minimum that the policy formulators in Malaysia could have pursued in this endeavour is to solicit expert knowledge from countries where such knowledge lies, like the OECD or other developed country blocs, where various kinds of data compilation on ICT have taken a firm footing. It was learnt that such an option was not fully explored by the user and statistical producer communities. This may be attributed to a lackadaisical attitude, or ignorance, or oversight on the part of policy formulators, who might not have maintained any professional linkage or contact with the statistical community at the international level.

Moreover, in most developing countries, the policy formulators and development planners usually depend upon advice and guidelines provided by the United $\mathrm{Na}$ tions Statistical Division (UNSD) to embark on new statistical initiatives. But in the case of ICT data collation, the UNSD is yet to embark on an organized and structured program for developing nations to leverage on. Most of the current efforts targeted at setting strategic directions and statistical guidelines are carried out by OECD, EUROSTAT and the United States in a collaborative manner.

The statistical community was also found to be insensitive to the changing user needs. It is also a rare occurrence in the developing world that statistical programmes are revised and improved to reflect new characteristics of the subjects being measured or to embrace new subjects as national priorities change [13]. Though this is partly an issue of professional competence, it can also be viewed in a broader sense as an integrity issue for the statistical profession, as it is to provide assurances on the provision of relevant professional services and good practices and at the same time reflect a strong sense of self-worth [18,21].

In the case of countries like Malaysia, there should be no excuse when the government has mobilized enormous resources in terms of policies and programme strategies and budget allocations, as well as branding and media publicity in popularizing new-age initiatives over the past two decades. In the medical profession, as Hutton points out; "the professional must do what is best for the patient" [19]. The professional statistical community should, using an outreach approach, adopt a statistical programme that best addresses the needs of the policy formulators and development planners at the macro level and development practitioners at the operational level, as well as informing the public at large.

\subsection{Limited understanding of ICT beyond technology}

The Population and Housing Census 2000 [10] marked the first initiative in the country to collect data on ICT diffusion at the household level [33,34]. The ICT items probed included radio/hi-fi, television, video/VCD/DVD, fixed telephone line, cellular phone, personal computer and Internet. Thereafter, similar data were collected whenever national household surveys were launched, beginning with the Household Basic Amenities Survey (HBAS) 2004, as a tag-on survey attached to the main National Household Income Survey (NHIS) or National Household Expenditure Survey (NHES). The primary purpose of HBAS is to collect information on the level of basic amenities enjoyed by households. As such, ICT items are also considered as one of the basic household amenities in Malaysia, alongside other items such as motor vehicles, air-conditioners, washing machines, refrigerators et cetera. Even a decade later in the Population and Housing Census 2011 and thereafter, ICT data collection was carried out with the same objective, scope and coverage, despite the fact that tremendous changes had occurred in the ICT products and services landscape. The uptake of fixed lines, fax machines, video and DVD have declined drastically at both the household and business sectors, but yet, this is still covered in the data collection activity. New ICT items, in particular wearable technology in such as Google glasses, smart watches, jewelry, headgear, belts, armwear, wrist-wear, legwear, footwear, skin patches, exoskeletons and e-textiles and Internet of Things embedded in smart devices, are increasingly penetrating at the household and enterprises levels but yet to be considered in the ICT data collection activity.

\section{On-going statistical measurement challenges in relation to ICT}

\subsection{Labour force measurement criterion}

The Internet has continuously challenged the validity of certain statistical concepts and definitions that 
are currently in use. For instance, it is not uncommon to find students, housewives, retired people and elderly people after the mid-sixties to be engaged in gainful employment vide Internet-driven working arrangements for at least one hour during the reference week that the Malaysian Labour Force Survey (MLFS) attempts to measure. Such changes in employment patterns pose direct challenges to the current definition of an outside labour force, which precludes those below 15 years and above 64 years old. Thus, data quality is what official statistical systems are primarily concerned about. Both the public policy formulators, development planners and official statistical community need to be aware that the current labour dynamics are different from what they have been experiencing in the preceding agro-industrial era.

\subsection{Shortfalls in the definition of ICT as per MSIC 2000 and MSIC 2008}

The definition of ICT has taken a new shape under MSIC 2008, which views the sector solely from the services perspective. In the earlier MSIC 2000, the definition of ICT sector entailed in one part the manufacturing components and the other part, the services components as per OECD recommendations [33]. The manufacturing components entailed items such as manufacturing of office, accounting and computing machinery; electrical machinery and apparatus; radio, television, communication equipment and apparatus; and medical, precision and optical instruments, watches and clocks. The services components entailed only telecommunication and computer services. The MSIC 2008 classification, which was derived from the International Standard Industry Classifications Revision 4 (ISIC Rev.4) recommendations, entails an additional four divisions, namely publishing activities, motion pictures/video/television/sound and music production, programming and broadcasting activities, and information activities have been added on in defining ICT Services, together with earlier telecommunication and computer services. Under the new classification, ICT production components are placed under the manufacturing sector and no longer under the information sector, thus giving rise to disruptions in the time series compilation; and more so, the user community are more confused as to which series to follow in setting and monitoring policy targets.

\subsection{Understatement of ICT services sector}

A close scrutiny of MSIC2008 revealed that the contribution of the ICT Services sector is understated after discovering that a number of ICT-relevant services industries had been precluded. These include telecommunications wiring (43212), computer network and cables television wiring (43213), satellite dishes installation (43214), wholesaling electrical and electronic services (46496), wholesaling of computer controlled machines (46593), retail sales of audio and video equipment (47420), musical records $(47,620)$, Internet retail auctions (47914), credit card services (64922), telephone based information services (63990), R\&D (72106), intellectual property (77440), call centre services (82200), desktop publishing (82192), mail box rental and mailing services (82195), digital printing (82196) and computer repair training (85222), as they are classified elsewhere as depicted by the codes in parenthesis. Further examination showed that some activities are not appropriately defined in the current classification. For instance, publishing activities (58) entails not only online publishing, but also traditional publishing of books, brochures and publications, which rightfully belong to the industrial order, not the KBE. Under estimation becomes accentuated when the contribution of new-age ICT services such as e-commerce, mobile commerce, outsourcing, broadband, electronic government services et cetera are classified under business services. A classification challenge is the convergence of technology and contents, which mars the functionality of the product; for example, a cellular phone is used not only for communication purposes but also as a camera, digital diary, mail box, directory et cetera.

\section{Emerging public policy and statistical concerns}

\subsection{Response to emerging policy demands}

Through an aggressive industrialization strategy, the unemployment rate in Malaysia has been well below $4 \%$ since the early nineties, the Asian Financial Crisis 1997 and Global Financial Crisis 2009 notwithstanding. In fact, the country has been importing cheap foreign workers especially to meet the labour shortages in the production, construction and food sectors. Many labour intensive industries have been relocated to newly-liberalized economies where the labour cost is cheap. In response to declining foreign 
direct investment (FDI) in labour-intensive sectors, the Malaysian Government has been promulgating knowledge-intensive industries, which saw the launch of MSC Malaysia in 1996. Being an ICT-intensive initiative, the structure of the Malaysian economy has been increasingly shaped and characterized by contemporary ICT-led innovation, $R \& D$, patenting intellectual property, commercialization of indigenous inventions, copyright, trademarks, acquiring globally-recognized certifications pertaining to quality, process improvement standards and developing competent workforce. In support of the KBE, the country has also been aggressively importing highly-skilled and competent workforce specializing in computing, information and communications technology, multimedia and creativity disciplines, especially knowledge workers from countries like India. Despite local shortages, the country has also been experiencing an outflow of talented workers especially ICT talents in search of better remuneration and career advancements in Asian and Englishspeaking destinations. Organizations tend to suffer when competent staff leave, especially those viewed as assets in an organization inventory. Since the education policy was liberalized in 1995, numerous private education institutions were established mainly to produce ICT graduates, but unfortunately enrolment has been on a downtrend with the average number falling from 100,000 in 2000 to 50,000 by 2014 [29,30]. Employability of new entrants to the workforce has also been a lingering challenge for the industry, especially when the ICT skills that higher learning institutions produce fail to match the contemporary industry needs. The MLFS that has been in force since the mid-seventies has failed to rise to the occasion of measuring new labour dynamics and worst still, some elements are considered out-of-date and obsolete.

\subsection{Technological advancements and statistical processes}

Despite technological advancements and broadband penetration standing at $67.1 \%$ in 2014 (31\% five years ago), much of the statistical processes in the country are still manual. The ICT-ization or informatization of statistical processes is rather slow and the progress has been incremental. The first ICTization of statistical process started in 2008, when for the first time DoSM introduced the Internet browser system and e-mail communication modes in data collection activities in the International Trade Survey. Thereafter, this procedure was repeated in the conduct of
Telecommunications, Computer and Information Survey (TCIS), Monthly Manufacturing Survey and Information Communication Services Survey. With this beginning, the last Population and Housing Census in 2010 also saw the adoption of e-mail communication systems in managing "drop off" and "pick-up" services in cases where self-administered questionnaires system were deployed. However, survey activities such as coding, editing and quality checking are still being carried out manually. Besides the limited version of esurveys, DoSM has also introduced handheld devices in the collection of consumer price data nationwide, but unfortunately data uploading or processing are still being carried out manually and not in real time. DoSM is also continually making efforts to expand the scope and coverage of an online data dissemination system in meeting customer aspirations but confined to only certain publication series. This effort is on an ad hoc basis and is too fragmented. Although e-surveys remain limited, the deployment of handheld devices and online data dissemination systems presumably have brought cost and time savings, accelerated response rates and increase in statistical operational efficiency as well as enhanced customer satisfaction. Such achievements are considered only marginal given the current rate and pace of technological advancements and digitization processes as well as online readiness of population and businesses.

\subsection{Cross-border transactions}

It is also pertinent to note that most, if not all, of the agro-industrial based statistical compilations are confined to national boundaries including trade statistics, which have implicit processes and documentations providing the requisite control over the flow of goods across borders. By comparison, in the information era, the profound impact of new-age ICT is not only confined to national boundaries but goes beyond borders. The challenge becomes accentuated in a globalized world. In particular, the scope and coverage of market liberalization and multilateral trade agreements allow even freer flow of goods, services and people across borders, making statistical accountability more complex especially cross-border transactions in e-commerce and mobile commerce. One of the challenges is the detailing out of capital flight acrossborders vide online transactions. The Central Bank may be able to monitor the total amount transacted across borders at a given point in time but lacks the details by type of services, which in practice is indeed a 
formidable challenge. Nonetheless, efforts are needed to gauge e-commerce transactions as accurately as possible by collecting data from e-commerce service providers and perhaps, financial institutions. This may require a review and realignment of the establishment sampling frame, as well.

\subsection{Collaboration with development agencies and industry associations}

The export and import of ICT services data published by DoSM differed significantly from similar data compiled from internal records of the MSC Malaysia programme, which is an ICT flagship managed by $\mathrm{MDeC}$. The export contributions from the MSC Malaysia programme alone registered an increase from $\$ 1.24$ billion in 2003 to RM11.5 billion in 2012 registering an AAGR of $20.2 \%$. In comparison, DoSM data showed only RM8.706 billion in 2012 for ICT services exports, indicating a large discrepancy in the data. Technically speaking, the DoSM figure covering the entire nation should be higher than the MSC Malaysia figure. Understandably, both organizations have different data collection approaches and strategies. Historically, DoSM has a long track record of publishing export and import data on merchandized goods, sourced from the periodic returns furnished by the Royal Malaysian Customs under the Ministry of Finance. Following the Government announcement on its aspirations to increase the share of services component to $70 \%$ by 2020 , DoSM in collaboration with the Central Bank of Malaysia commenced the compilation of export and import data on ICT Services, but using indirect estimation procedures. In comparison, MSC Malaysia collects data from ICT companies that come under its purview, but it uses a periodic reporting system. Data is collected by technology clusters entailing software, mobility, embedded software and hardware $(\mathrm{MeSH})$, shared services and outsourcing, creative multi-media, internet based businesses and institutes of higher learning (IHL) incubators. Such data discrepancies can only be sorted out provided data compilation agencies speak the same statistical language. Therefore, it is imperative for statistical organizations to work closely with development agencies and industry associations which are highly networked with their member companies.

\subsection{Increasing role of the private sector in official statistical compilation}

Data collection on ICT occupation and industry has been a regular feature in the MLFS since its inception in the mid-seventies. But, occupation and industry data has been disseminated only at the one digit level as per the Malaysian Standard Classifications Occupations (MASCO 1998) and MSIC 2008. Since 2010, the number of employed persons in information and communications has become a regular feature in the MLFS publication but the numbers have been fluctuating, from 207,600 in 2011 to 209,200 in 2012 , before declining to 191,300 in 2013; the undulating trend is due to sampling fluctuations. Besides that, detailed data on ICT occupations at two or three digit levels pertaining to IT managers, computer professionals and electronics, telecommunication engineers, data entry operators and telemarketers are not published, but instead subsumed under one-digit professional and managerial categories. However, the demand for ICT occupation data at two or three digit levels are highly sought by both public policy formulators and private sector practitioners. In the absence of official data, mainstream policy makers and planners are increasingly turning to private sector sources. One such area often referred to is the salary profile of ICT professionals published by The National ICT Association of Malaysia, popularly known as PIKOM [30]. The salary profile entails the average salary by industry, ICT segments, job category, work experience, employment size, location, job function and regional benchmarking. Such level of details is usually not tenable in sampling surveys unless the sample size is increased; which can be a costly affair. Being market-focused, the quality of private sector data is typically questionable [39]. Perhaps, the national statistical office could play an extended role in validating the reliability of all private sector data before they are used in public policy activities.

\section{Way forward strategy}

The paper comes to the conclusion that the current agro-based statistical concepts and definitions are unable to gauge KBE developments accurately. In meeting new-age policy formulation and planning needs, the paper calls for reinventing the official statistical system leadership, in particular promulgating the migration from agro-industrial based settings to an information-age statistical system. This may require a review of the validity of current statistical concepts and definitions in the context of contemporary ICT development; distinctly defining the information sector as an economic sector by restructuring the current industry, product, trade and occupational classification sys- 
tems; instituting holistic and pragmatic approach in instituting new data compilation mechanisms on ICT and $\mathrm{KBE}$ entailing new national-level surveys and exploring administrative records of regulatory and development institutions; records probing ICT and KBE developments; technologizing statistical processes towards increasing efficiency and efficacy aimed at producing timely, valid and reliable statistics at reduced cost; exploring collaboration with private sector industry associations who have online and real time connectivity and interactivity with their members especially in data collection activity; and more importantly, enhancing the competency of the statistical community through interdisciplinary approaches. These require not only national-level political will and administrative commitments but also advocacy and intervention by international statistical organizations especially United $\mathrm{Na}$ tion Statistical Development (UNSD) and international statistical organizations who, like in the past, could play a significant role in shaping a harmonious and comparable statistical system globally.

\section{References}

[1] D.N. Abdulai, From A Production Based Economy to a Knowledge Based Economy: The Road Ahead For Malaysia. Paper presented at K-Based Economy: Forging Ahead For National Transformation. Sixth National Civil Service Conference, 28-30 June 2001. INTAN Kuala Lumpur, 2001.

[2] A.H. Ali, Foreword "Towards Malaysia's Knowledge Empowerment in the 21st Century", NITC Malaysia Publication, Access, Empowerment and Governance in the information Age: Building Knowledge Societies Volume 1, 2000.

[3] S. Berman et al., Digital Reinvention Preparing for a Very Different Tomorrow. IBM Institute for Business Value. IBM, 2014.

[4] S.J. Berman and R. Bell, Digital transformation: Creating new business models where digital meets physical, IBM Institute for Business Value. April 2011.

[5] S. Bhatnagar, ICTs to build a vibrant knowledge society, Information for Development (i4d), Volume IV, Number 3, March 2006, 29-30.

[6] D. Carlton, The Nexus of Forces: Social, Mobile, Cloud and Information. Gartner Research, 2012.

[7] M. Castells, The Internet Galaxy. Oxford \& New York: Oxford University Press, 2001.

[8] C. Christensen, The Innovator's Dilemma: The Revolutionary Book That Will Change the Way You Do Business. Harper Business, 2011, p. 336. ISBN 0062060244.

[9] C. Christensen, Disruptive Technologies Catching the Wave, Harvard Business Review (January 1995), p. 3.

[10] DOSM (2000). Population and Housing Census 2000 Report. Published by Department of Statistics Malaysia (DOSM).

[11] P.F. Drucker, Management Challenges for the 21st Century, 1999, pp. 97-132.

[12] P.F. Drucker, Post Capitalist Society, Harper Collins, 1993, pp. 165-176.
[13] J.W. Duncan, Integrity in Official Statistics. Available at: http: //findarticles.com/p/articles/mi m1094/is n3 v28/ai 143229 83/, 1993.

[14] Earl (1999). The Shift from the Industrial to the Information Age. Extract from Turner, Collin (2000). The Information Economy. Business Strategies for Computing in the Digital Age.P-2.

[15] R. Edmunds and T. Marchant, Official Statistics and Monitoring and Evaluation Systems in Developing Countries: Friends or Foes? The Partnership in Statistics for Development in the 21st Century. Paris 21, OECD, 2008.

[16] EPU, (2001). The Third Outline Perspective Plan (2001-2010 OPP3 (2001)). Economic Planning Unit (EPU), Prime Minister's Department, Malaysia.

[17] M. Graham, Warped Geographies of Development: The Internet and Theories of Economic Development, Geography Compass 2(3) (2008), 771-789.

[18] J.L. Hutton, Medical Ethics and Statistics, in: in Encyclopaedia of Biostatistics, P. Armitage and T. Colton, eds., Wiley Chichester, 1998, pp. 2540-2546.

[19] IMF, (2007) International Monetary Fund (2007). The Special Data Dissemination System: guide for subscribers and users.

[20] N. Ingelbrecht, Cognizant Computing: The Next Era of Computing is Personalized. Gartner, 2014.

[21] J. Kultgen, Ethics and Professionalism. Philadelphia: University of Pennsylvania Press, 1988.

[22] R. Mansel and U. When, Knowledge Societies: Information Technology for Sustainable Development. United Nations Commission on Science and Technology for Development, Oxford University Press, 1998, p-66-79, p-82-89.

[23] J. Manyika, Disruptive technologies: Advances that will transform life, business, and the global economy. McKinsey Global Institute. McKinsey and Company, 2013.

[24] M. Nair, The DNA of the new economy, Economic Bulletin 8 (2007), 27-59.

[25] M. Nair and T.M.A. Shariffadeen, Managing innovation in the network economy: lessons for countries in the Asia-Pacific region, Digital Review of Asia Pacific 2009-2010, (2009), pp. $25-42$.

[26] R. Oines, System of National Accounts (SNA) 1968. Internal Working Document of Department of Statistics, Malaysia, 1976.

[27] R. Pepper, E.J. Rueda-Sabater, B.C. Boeggeman and J. Garrity, From mobility to ubiquity: Ensuring the power and promise of internet connectivity ...for anyone, anywhere, anytime. Geneva, Switzerland: World Economic Forum, 2009.

[28] PIKOM, ICT Strategic Review: Innovation the Way Forward. Published by The National ICT Association of Malaysia (PIKOM). Petaling Jaya. Malaysia, 2009.

[29] PIKOM, ICT Strategic Review: e-Commerce for Global Reach. Published by The National ICT Association of Malaysia (PIKOM). Petaling Jaya. Malaysia, 2010.

[30] PIKOM (March 2010). ICT Job Market Outlook in Malaysia. Kuala Lumpur, Malaysia.

[31] M.A. Rahman, IT for Competitive Advantage Opportunities for Development. Bangladesh Computer Council - Conference Proceedings September 17-20, 1990. Putra World Trade Centre, Kuala Lumpur Malaysia.

[32] Ramachandran, Measuring Knowledge Development and Developing Official Statistics for the Information Age, International Statistical Review 71(1) (2003), 83-107. Hague. Netherlands.

[33] Ramachandran and Vigneswarer, Statistical Compilation of ICT Sector in Malaysia publication. Published by Orbicom, 
the International Network of UNESCO Chairs in Communication 2011, 2011.

[34] R. Ramachandran, Measuring Information Development in the New Millennium. Thesis submitted in fulfilment of the requirement for the degree of Master of Philosophy (by research). Faculty of Management Multimedia University, Malaysia, 2008.

[35] S. Saleh, Prelude chapter: Disruptive Innovation the Way Forward for High Value Adding Economy published in ICT Strategic Review 2012/13: Innovation for Digital Opportunities. PIKOM Publication Series. Malaysia, 2012.

[36] A. Shariffadeen, The changing World: ICT and Governance.
NITC Malaysia Publication, 2000. Paper 1: Access, Empowerment and Governance in the Information Age: Building Knowledge Societies, 2000, Vol. 1, pp. 1-14.

[37] D. Tapscot, Creating Value in the Networked Economy. Harvard Business school press, 1999.

[38] UN, Case Studies in Population Policy Malaysia. Population Policy Paper No. 14. Department of International Economic and Social Affairs, United Nations, New York, 1987.

[39] A.W. Wyckoff, OECD Efforts to Address the Measurement and Policy Challenges posed by the Information Society. Paper presented at IAOS Satellite Meeting on Statistics for the Information Society, 30-31 August 2001, Tokyo Japan. 